\title{
A Study on the Effect of Stratified Mixture Formation on Combustion Characteristics in a Constant Volume Combustion Chamber*
}

\author{
Kihyung LEE**, Changhee LEE ${ }^{* * *}$ and Haeyoung JEOUNG ${ }^{* * *}$
}

\begin{abstract}
It is well known that a lean burn engine caused by stratified mixture formation has many kinds of advantages to combustion characteristics, such as higher thermal efficiency and lower $\mathrm{CO}$, NOx levels than conventional homogeneous mixture combustion. Although this combustion can achieve low fuel consumption, it produces much unburned hydrocarbon and soot because of inhomogeneity of the charge mixture in the combustion chamber. Therefore, it is necessary to investigate the effect of mixture formation on combustion characteristics in order to obtain the stable lean combustion. In this paper, fundamental studies for stratified combustion were carried out using a constant volume combustion chamber. The effect of mixture formation on the combustion characteristics in the chamber was examined experimentally. In addition, the effect of turbulence on stratified charge combustion process was observed by schlieren photography. From this study, as the swirl intensity increases, $(S v)_{\max }$ is rapidly enhanced and the period of combustion is shortened. We also find that the stratification degree can be quantified by using burning velocity and it was controlled by induced air pressure and turbulent intensity.
\end{abstract}

Key Words: Stratified Mixture Formation, Constant Volume Combustion Chamber, Mass Burned Fraction, Swirl Intensity, Direct-Injection Spark Ignition (DISI), Stratification Degree

\section{Introduction}

As the environmental problems caused by vehicle exhaust emissions become more severe, exhaust emission standards and fuel economy regulations become more stringent. For the gasoline engine, the emission of $\mathrm{CO}_{2}$, which is one of the main causes of global warming, becomes a severe problem as well as the emission of toxic gases such as $\mathrm{CO}, \mathrm{HC}$, and $\mathrm{NO}_{\mathrm{x}}$. Recently, the DISI (direct injection spark ignition) engine is spotlighted as a next generation engine that can satisfy the SULEV (Super Ultra Low Emission Vehicle) regulation and can reduce the fuel consumption. Thus, the studies of stratified mixture formation, one of the key parts for the development of DISI engine, have been performed by many researchers ${ }^{(1),(2)}$.

* Received 22nd November, 2004 (No. 04-5182)

** Department of Mechanical Engineering, Hanyang University, 42-791 Korea. E-mail: hylee@ hanyang.ac.kr

*** Department of Mechanical Engineering, Hanyang University, 42-791 Korea. E-mail: leemech@ @anyang.ac.kr, Haeyoung@ hanyang.ac.kr
As for stratification, many studies had been carried out using the modified diesel injection system in early phase. The injector used in these studies may result in misfiring in light load operation and generating the smoke in high load operation. Recently, many researches have been conducted by using common rail type injection system with highly flexible control ability. In these systems, premixed mixture is used in high load range to prevent smoke generation, and then the stratified mixture has focused on the improvement of fuel economy in light load operation. Though several DISI engine systems have been put into market with acceptable power and operation stability, the effort to enhance stratification features is still progressing and the researches on this subject have just started $^{(3)-(5)}$.

In this study, an experimental apparatus including a constant volume combustion chamber was manufactured in order to simulate the combustion system of an actual DI gasoline engine. The stratification degree and swirl intensity were analyzed using indicated pressure analysis and combustion visualization in order to investigate the early 
phase of burning velocity. Besides, the stratification degree was introduced to evaluate the stratified mixture formation and we measured the flame speed as the stratification degree in the constant volume combustion chamber. The stratified combustion was achieved by this way that the fuel is injected to the vicinity of spark plug by the hollow cone type injector. From the experimental result, we found that the turbulence intensity generated by the swirl flow in the chamber enhances the flame propagation speed and promotes the air fuel mixture.

\section{Experimental Apparatus and Methods}

\subsection{Experimental apparatus}

Figure 1 shows the experimental apparatus used in this study. The following experimental equipments were used by this study: a premixed chamber, high pressure fuel supply equipment for providing fuel to the injector, a turbulent flow generator for making a swirl in the combustion chamber, a hollow cone type injector, heating system for controlling the combustion chamber temperature, an ignition system of the CDI (capacitor discharge ignition) type device for generating ignition energy, pressure and temperature measuring equipment, injection and ignition synchronous control equipment, and a data processing system.

Figure 2 shows a schematic diagram of the constant volume combustion chamber used in this study. The internal diameter and width of the chamber were $100 \mathrm{~mm}$ and $30 \mathrm{~mm}$, respectively. The volume capacity was $236 \mathrm{cc}$. The material of the combustion chamber was duralumin, which has excellent durability and thermal diffusivity. We used a piezo-electronic pressure sensor for measurement of the combustion pressure and the amplified electrical signals (PCLD-789) obtained from the pressure sensor is converted to the pressure data which will be shown in later results using the calibration curve. A heater $(100 \mathrm{~W})$ was attached to the chamber wall to control the initial temperature. The solenoid valve was installed to generate swirl flow in constant volume combustion chamber. A spark plug is located on the midsection to make the injected fuel concentrate on the vicinity of spark plug. Quartz glasses, $30 \mathrm{~mm}$ thick, were placed on both sides of the combustion chamber for observing spray behavior.

\subsection{Experimental procedure}

It is known that the gasoline fuel is in a liquid state at a normal temperature. For this reason, there are many possibilities for misfire when fuel is directly injected into a combustion chamber. To realize stratified combustion, the temperature of the combustion chamber is fixed at the evaporation temperature $(443 \mathrm{~K})$ of gasoline.

The equivalence ratio of the chamber was $0.8,0.6$, 0.4 , and 0.2. The total equivalence ratios of 30,50 , and $70 \%$ were applied to the combustion chamber after sufficient mixture, which gives various values to the mix-

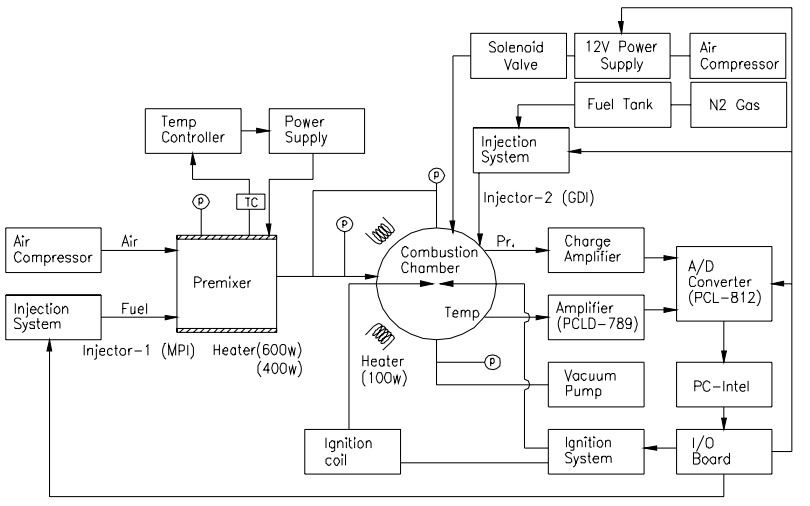

Fig. 1 Schematic diagram of experimental apparatus

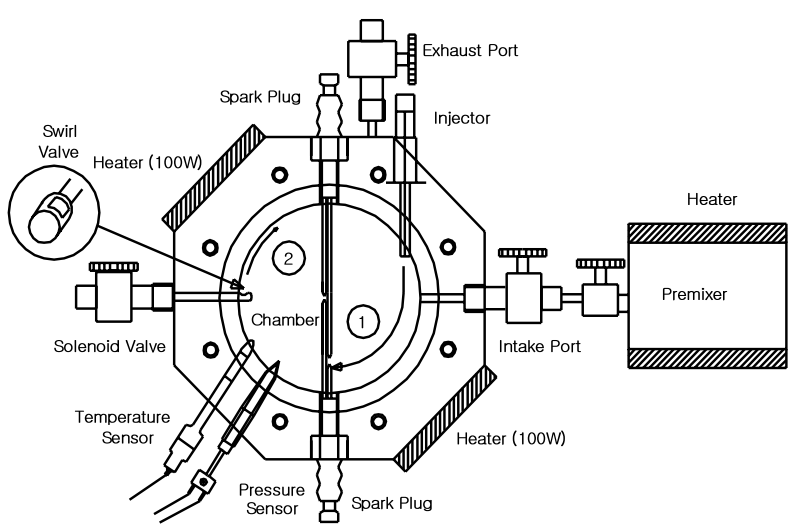

Fig. 2 Schematic diagram of constant volume combustion chamber

ture distribution in combustion chamber. The combustion characteristics according to mixture distribution are analyzed by the condition of directly injected fuel of 30, 50, and $70 \%$ in the combustion chamber. The ignition begins at $3 \mathrm{msec}$ after fuel injection and the ignition duration is fixed at $10 \mathrm{msec}$. In addition, the equivalence ratio of injected fuel in the combustion chamber was controlled by injection duration. Turbulence was created by opening a solenoid valve that is able to inject the air in the parallel direction with the chamber wall to realize the stratified combustion.

The swirl intensity was controlled by the pressure air and the equivalence ratio of the combustion chamber was controlled by the open and close timing of the solenoid valve. The meaning of "Dir" is defined as the rate of direct injection from the injector and the meaning of "Pre" is defined as the rate of pre-mixture injection from the premixer chamber. Table 1 shows the experimental conditions.

\subsection{The quantitative method of stratification de- gree}

Stratification degree is used to represent of the ratio of the fuel that joins in forming the nearly stoichiometric mixture and the total amount of injected fuel. The requisites for enhancing this ratio are 
Table 1 Experimental conditions

\begin{tabular}{|l|l|}
\hline Experimental Variables & Conditions \\
\hline Equivalence Ratio & $0.2,0.3,0.4,0.8$ \\
\hline Ambient Pressure (MPa) & $0.3,0.5,0.7$ \\
\hline Ambient Temperature (K) & 443 \\
\hline Injection Pressure (MPa) & 10 \\
\hline Ignition Duration (msec) & 10 \\
\hline Mixture Distribution(Dir:Pre) & $100: 0,70: 30,30: 70,0: 100$ \\
\hline Induced Air Pressure (MPa) & $1,0.8,0.6$ \\
\hline
\end{tabular}

( a ) to reduce the amount of unburned fuel, and

(b) to enhance the ratio of the mixture area with air fuel ratio near the stoichiometric value against the flammable mixture area.

The mixture, which is a little richer than the stoichiometric state, brings about the highest burning velocity. Therefore, to satisfy both requisite (a) and requisite (b), it is necessary to enhance the burning velocity in the broader mixture area. Taking this concept into consideration, the maximum volumetric burning velocity $(S v)_{\max }$ is assumed to be reasonable as a stratification degree ${ }^{(1),(6)}$.

Volumetric burning velocity $S_{V}$ is given by

$$
S_{V}=A_{f} \cdot S_{u}
$$

where $A_{f}$ is the flame front area and $S_{u}$ is the burning velocity. Next, the mass burned fraction $\dot{m}_{f}$ is given by

$$
\dot{m}_{f}=A_{f} S_{u} \cdot \rho_{u} \frac{1}{A F+1}=S v \cdot \rho_{u} \frac{1}{A F+1}
$$

where $A F(=15)$ is the air-fuel ratio in mass and $\rho_{u}$ is the mixture density at the fresh side of the mixture. The net heat supply rate $d Q / d t$ is introduced based on the first law of thermodynamics,

$$
\frac{d Q}{d t}=\frac{V}{\kappa-1} \frac{d P}{d t}
$$

Where $Q$ is the net heat quantity supplied during time $t$ and $V$ is the chamber volume. Neglecting the heat loss through the chamber wall, which is estimated to be about $20 \%$ of the heat supply rate based on result (a) in section 2.2, the above value is equal to $H_{u} \dot{m}_{f}$. Then, the following equation is obtained:

$$
\left(H_{u} \dot{m}_{f} \equiv\right) H_{u} \cdot S_{v} \cdot \rho_{u} \frac{1}{A F+1}=\frac{V}{\kappa-1} \cdot \frac{d P}{d t}
$$

Here, it is assumed that, under the highest $S v$, the mixture near the flame front has an $A F$ of 15 , which is hereafter denoted by $(A F)_{V b \max }$. In addition, the relation of $\rho_{u}=\rho_{0}\left(P / P_{0}\right)^{1 / \kappa}$ is obtained by applying the law of adiabatic change to the state of the fresh side mixture. Then, $(S v)_{\max }$, the highest $S v$, is given by

$$
\left(S_{V}\right)_{\max }=\frac{\left\{(A F)_{V b \max }+1\right\} V}{H_{u} \cdot(\kappa-1) \cdot \rho_{o}} \cdot\left[\frac{1}{\left(P / P_{0}\right)^{1 / \kappa}} \cdot \frac{d P}{d t}\right]_{\max } \text { (5) }
$$

Where $\rho_{0}$ is the initial ambient air density and $P_{0}$ is the initial chamber pressure, which is equal to $P a$. The pressure rise rate $d P / d t$ in this equation may be replaced by the "indicated" pressure rise rate.

It should be noted that the above $(S v)_{\max }$ indicates the average value over the entire flame front area, as Eq. (5) was induced based on a macroscopic consideration that neglected the local behavior of various factors, such as fuel vapor concentration and turbulence. It should also be noted that $(S v)_{\max }$ is to take a $20 \%$ higher value than that calculated by Eq. (5), since $H_{u} \dot{m}_{f}$ in Eq. (4) should be replaced by $0.8 H_{u} \dot{m}_{f}$, if heat loss through the chamber wall is taken into account.

As shown in Eq. (5), $(S v)_{\max }$ is determined using $P$ and $d P / d t$ data obtained by pressure analysis, and $(S v)_{\max }$ is closely related to $(d P / d t)_{\max }$. This means that the adverse effects on both requisites (a) and (b) reflect on $(S v)_{\max }$, while the adverse effects on requisite (a) only reflect on $\eta_{h}$, suggesting that $(S v)_{\max }$, related to $(d P / d t)_{\max }$ or $\dot{m}_{f}$, is suitable for widespread evaluation of the stratification feature. $\eta_{h}$ evaluates only requisite (a). The correlation between $(S v)_{\max }$ and $(d P / d t)_{\max }$ is investigated to clarify the possibility of replacing $(S v)_{\max }$ with $(d P / d t)_{\max }$. Therefore, $(S v)_{\max }$ was proven to be useful as a stratification degree, representing widespread stratification feature quantitatively.

\section{Result and Discussion}

\subsection{Combustion characteristics according to the mixture distribution}

3.1.1 Effect of mixture distribution on a combustion pressure Figure 3 represents the combustion pressure history with the condition of mixture distributions when the ambient pressure is $0.5 \mathrm{MPa}$ and $0.7 \mathrm{MPa}$. Where, the definition of "Dir" is direct injection rate and that of "Premix" is pre-mixture injection rate which is mixed the air and fuel in hot combustion chamber.

When fuel is directly injected to the combustion chamber, the peak combustion pressures of both cases are higher than other mixture distributions and combustion pressure is also rapidly reached at the maximum combustion pressure. From this figure, we assume that the stratified combustion is occurred when the rich mixture is formed near the spark plug.

Figure 4 shows the maximum combustion pressure and the arrival time of peak combustion pressure with various mixture ratios at an ambient pressure range of $0.1 \mathrm{MPa}$ to $0.7 \mathrm{MPa}$. We find that combustion pressure increases in accordance with an increase of the direct injection ratio. The result of Fig. 4 (b) reveals that the arrival time of maximum combustion pressure is shortened as the percentage of mixture distribution increases. In addition, we know that the maximum pressure is increased in accordance with the increasing the ambient pressure of the chamber and the ratio of direct injection. The reason for this trend is believed that the swirl flow produced by di- 


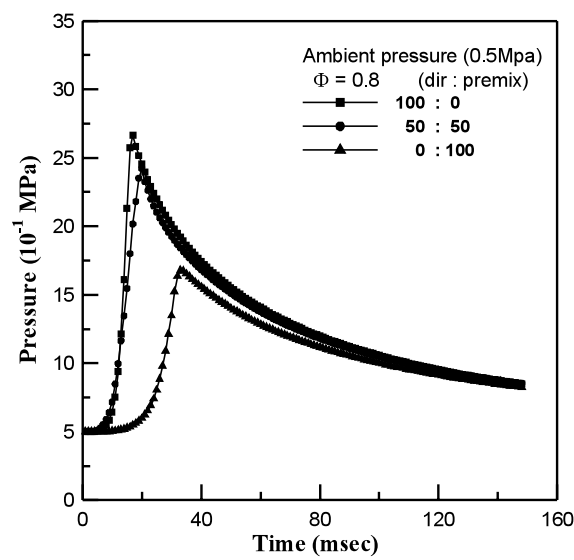

(a) $P a=0.5 \mathrm{Mpa}$

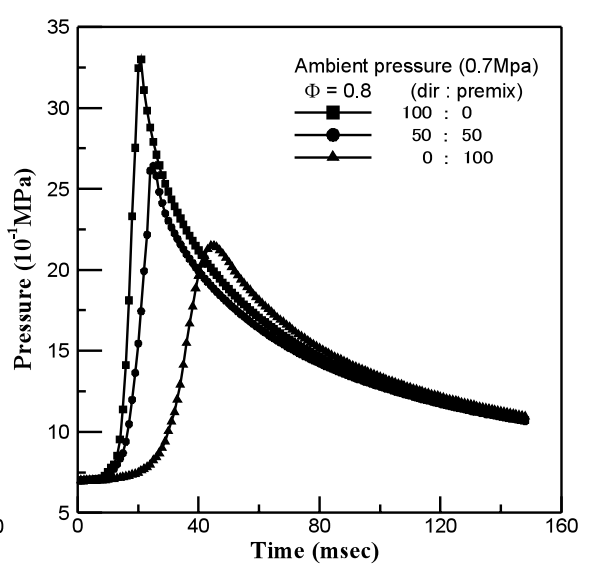

(b) $P a=0.7 \mathrm{MPa}$

Fig. 3 Effect of mixture distribution on the combustion pressure

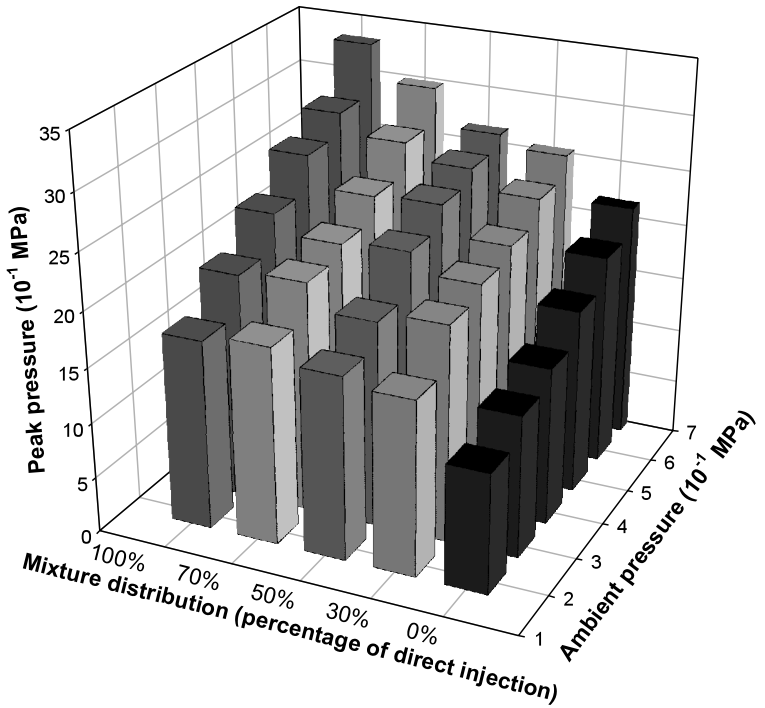

(a) Peak pressure

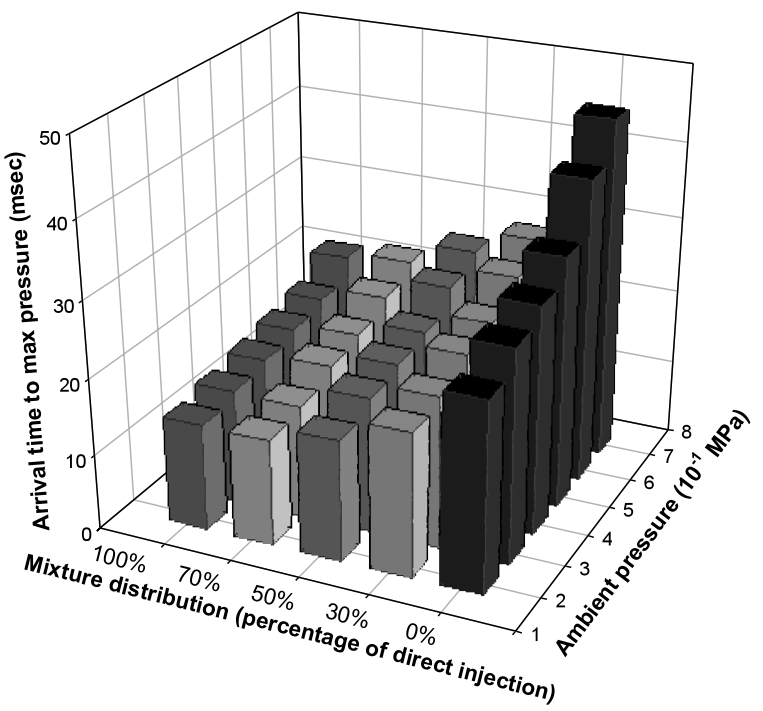

(b) Arrival time to maximum pressure

Fig. 4 Effect of mixture distribution and initial pressure rected injection air enhances combustion characteristics.

\subsubsection{Mass burned fraction with mixture distribu-}

tion Mass burned fraction is calculated based on the pressure data obtained from the experimental results as follow $^{(7)}$ :

$$
M_{f}(t)=\frac{P(t)-P_{i}}{P_{\max }-P_{i}}
$$

Where $P(t)$ is the combustion pressure, $P_{i}$ is the initial mixture pressure, and $P_{\max }$ is the maximum combustion pressure. If the mixture gas is fully burned when it reaches peak combustion pressure, it can be calculated according to the relative value of the combustion pressure, where M10 stands for 10 percent combustion and M100 stands for 100 percent combustion.

Figure 5 shows the mass burned fraction according to the mixture distribution and initial ambient pressure in the case of the lean equivalence ratio 0.8 . As the initial pressure is higher, the combustion period is longer. The higher ratio of pre-mixture tends to bring about the longer is the longer combustion period. In the case of 100 percent direct injection, the curve of the combustion rate is steep because the equivalence ratio at the vicinity of the spark plug is rich. On the other hand, as the pre-mixture ratio is bigger, the curve of combustion rate is more inactive because the fuel density of the mixture is lean. This is caused by power reduction due to longer combustion period. However, the combustion period moves downward $20 \mathrm{msec}$ in stratification combustion for the same equivalence ratio.

\section{2 Combustion characteristics in combustion chamber according to a turbulent flow}

3.2.1 Combustion characteristics with equivalence ratio Figure 6 shows the comparison of the combustion pressure with swirl flow generated by inducing the pressurized air. The equivalence ratio and ambient pressure in the combustion chamber are controlled by the injection duration of air induced from the solenoid valve. After air was induced into the combustion chamber through the solenoid valve, fuel was injected into the 


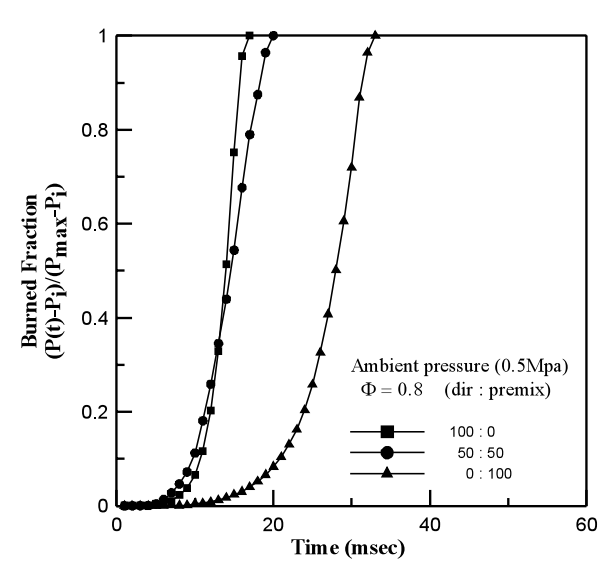

(a) $P a=0.5 \mathrm{MPa}$

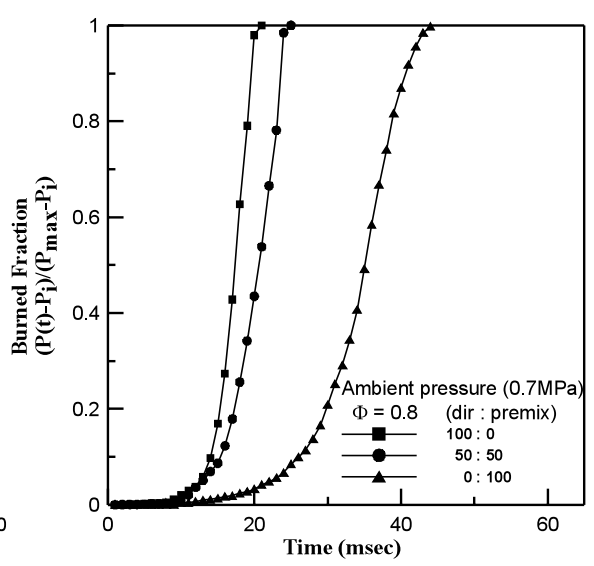

(b) $P a=0.7 \mathrm{MPa}$

Fig. 5 Effect of mixture distribution on the mass burned fraction

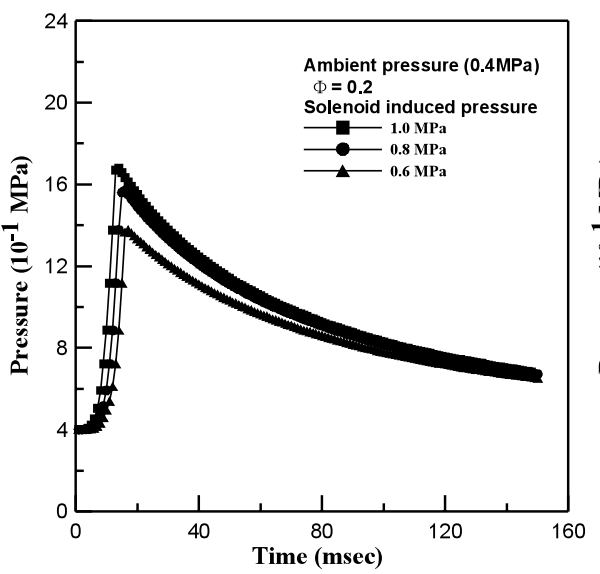

(a) $\Phi=0.2$

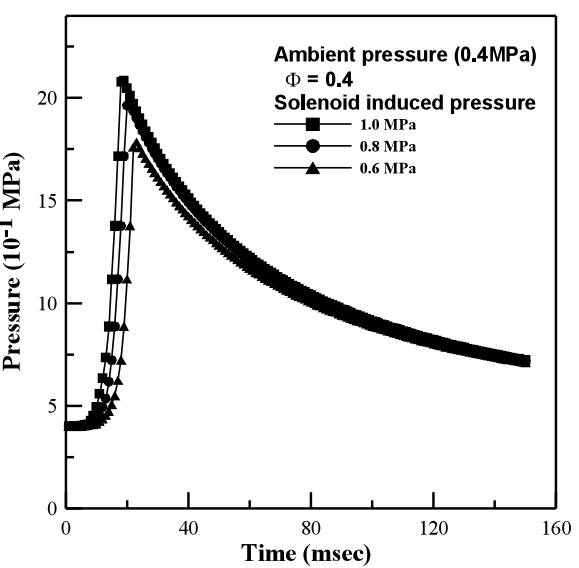

(b) $\Phi=0.4$

Fig. 6 Effect of the swirl flow on the combustion pressure

chamber by the injector. For the purpose of calculating the equivalence ratio, the air mass of induced air pressure is measured by controlling solenoid valve opening time and injection rate is also measured by controlling the injection duration. Using these values, we obtained the equivalence ratio which is the ratio of the air mass of induced air pressure and injection rate. In case of premix combustion, we supplied the premixed gas to the chamber and then remained fuel among total amount was directly injected into the combustion chamber. The arrival time to the peak combustion pressure was extremely increased as the inducing pressure increases. This is believed to the fact that the swirl flow increases the flame area and promotes air fuel mixture formation.

\subsubsection{Flame propagation velocity with swirl flow} The burning velocity of flame $(S(t))$ was obtained from mass conservation equation of the unburned mixture.

$$
S(t)=\frac{d M / d t(t)}{A(t) \cdot \rho(t)}
$$

In this manner, the burning velocity of the flame according to the elapsed combustion time had to be used to evaluate the mass burned fraction, the flame area, and the density of the unburned mixture over the duration of the combustion period. Therefore, to obtain the respective terms, the pressure in combustion chamber was measured and the flame propagation velocity was obtained using the visualization of flame propagation process.

Figure 7 shows the burning velocity of the flame propagation according to the swirl intensity in the combustion chamber when equivalence ratio was 0.2 and 0.4 . The flame shape produced by swirl is different from the premixed flame, which is very complex. It is difficult to calculate the exact flame area because it was not propagated in form of spherical flame shape. The burning velocity is increased as the combustion is proceeds. The time of the maximum burning velocity is around $17 \mathrm{msec}$ after the outset of combustion. It has a tendency to decrease after $15 \mathrm{msec} \sim 20 \mathrm{msec}$ at the end of combustion passes. In addition, burning velocity is very fast due to the effect of the swirl intensity in the case of $1 \mathrm{MPa}$ of induced pressure. From these results, we find that the increasing swirl intensity promotes combustion effects. As swirl intensity increases, the increase of mass burned fraction is more effective than the increase of the flame area and the density 


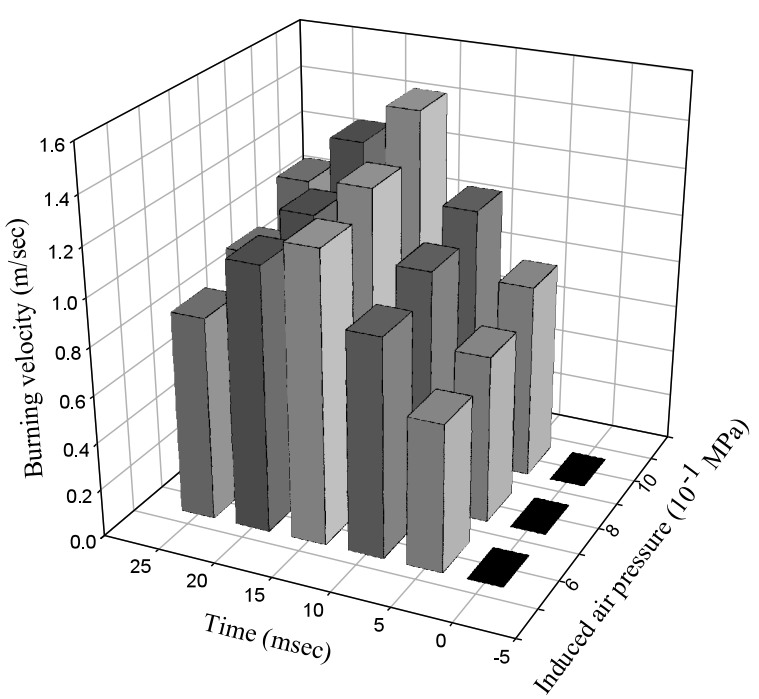

(a) $\Phi=0.2, P a=0.3 \mathrm{MPa}$

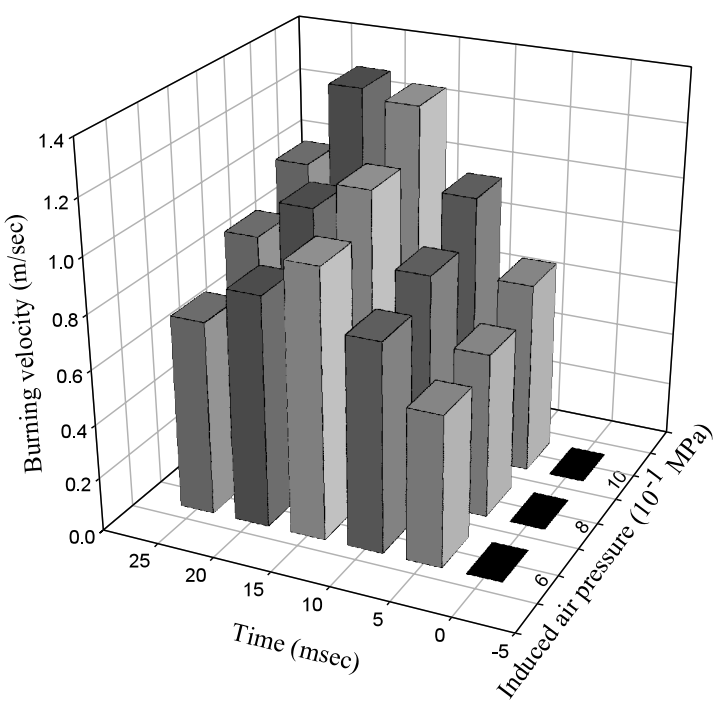

(b) $\Phi=0.4, P a=0.3 \mathrm{MPa}$

Fig. 7 Effect of swirl intensity on the burning velocity

of the unburned mixture. This phenomenon is caused by the effect of enhanced combustion due to increased turbulent intensity. The reason for this trend is also believed that the effect of increased mass burned fraction due to increased turbulent intensity is larger than that of increased flame area and density of unburned mixture gas.

\subsection{The characteristic of flame propagation with mixture distribution}

Figure 8 shows the characteristics of flame propagation captured by high-speed camera in the case of ambient pressure $0.3 \mathrm{MPa}$ and the ultra lean equivalence ratio 0.2. When mixture distribution is 100 percent of direct injection, the period of flame propagation is shortest and this is larger as the pre-mixture ratio increases. When the premixture is formed in the combustion chamber, combustion becomes unstable because the density of the stratified mixture around spark plug is diluted. Therefore, we find that combustion efficiency is good and close to flammable

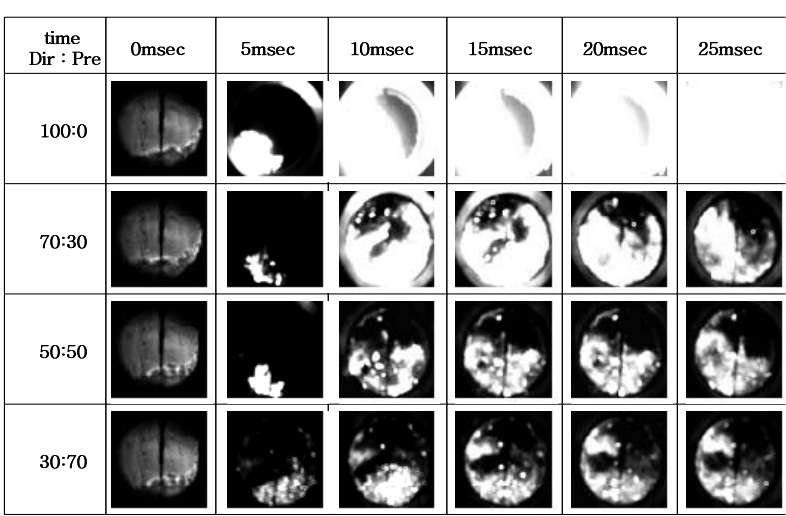

Fig. 8 Flame propagation process $\Phi=0.2 \& P a=0.3 \mathrm{MPa}$

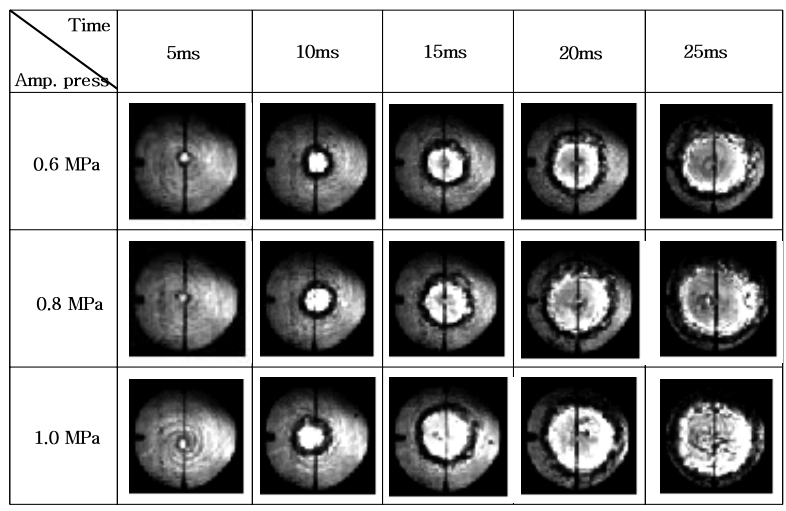

Fig. 9 Fuel stratification and flame propagation process with swirl intensity $(\Phi=0.2, P a=0.3 \mathrm{MPa})$

limits in the case of the equivalence 0.2 and 100 percent direct injection. This result revealed that the flame propagation characteristics obtained in this study agree with the concept in actual DISI system development.

Figure 9 shows the fuel stratification process and flame propagation process with swirl intensity obtained from the schlieren method. In the figure, the time of the horizontal axis was $0 \mathrm{msec}$ at the ignition point. Generally it became known to increase the turbulent intensity and swirl ratio in accordance with increasing induced-air pressure from Ref. (4). As swirl intensity increases, the period of fuel stratification around spark plug is shortened and the vortex around fuel droplet becomes wider. From these results, it is expected that combustion duration decreased owing to the increase of flame area and intensified flow field and that this combustion is close to flammable limits.

\section{4 Stratification degree with the mixture distribu- tion}

3.4. 1 Combustion characteristics according to ignition period Figure 10 (a) and (b) shows the combustion characteristics according to the ignition period. The ambient temperature was $463 \mathrm{~K}$ and the fuel was injected after air was injected at a constant volume combustion chamber through the solenoid valve. Figure 10 (a) 


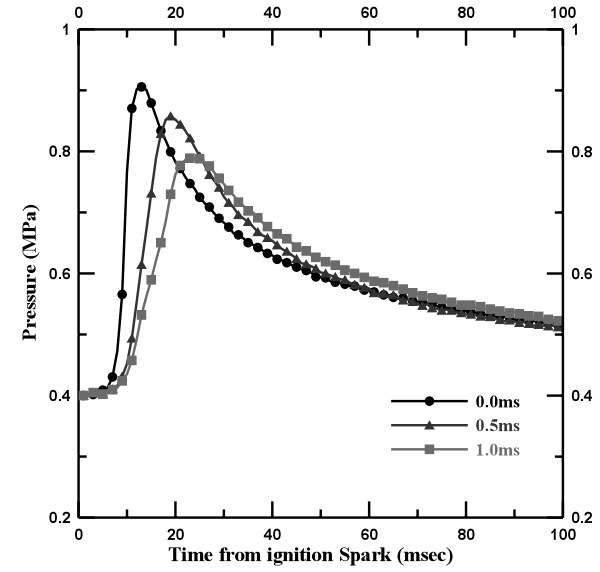

(a) $\tau_{\text {int }}$ on $P$ traces

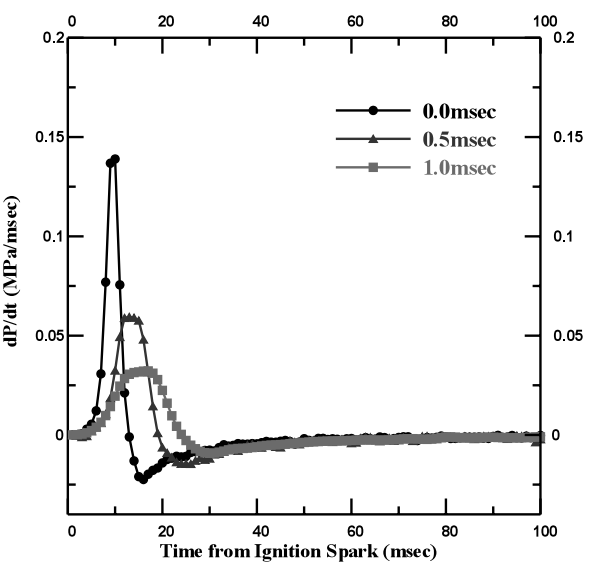

(b) $\tau_{\text {int }}$ on $d P / d t$

Fig. 10 Effect of $\tau_{\text {int }}$ on $P$ and $d P / d t$ traces

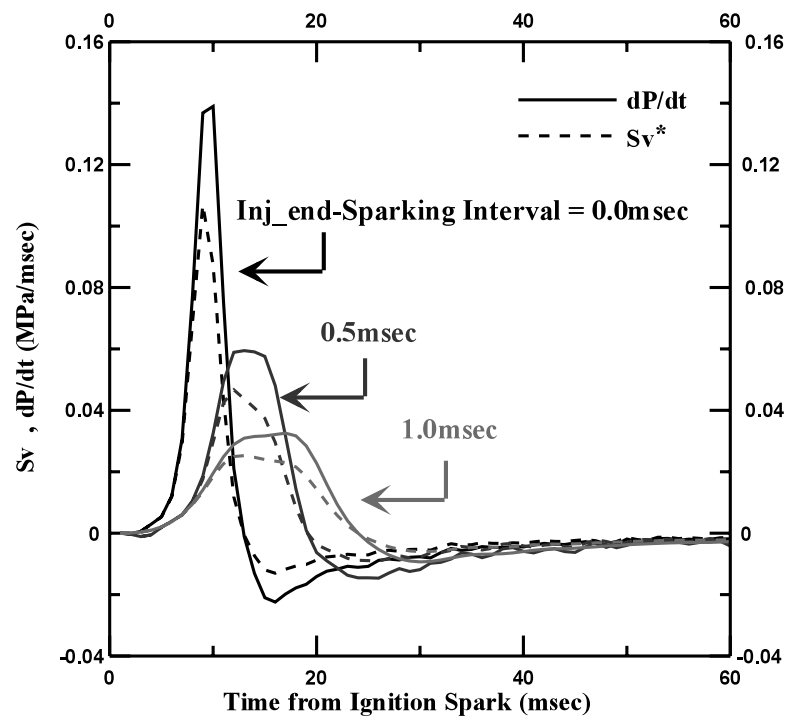

Fig. 11 Comparison between of $(S v)^{*}$ and $d P / d t$

shows the combustion pressure in accordance with spark interval after injection start. Figure 10 (b) is the result of combustion pressure data converted by using Eq. (4). The result showed that rate of pressure rise is increased in the combustion chamber when it was ignited at $0 \mathrm{msec}$, $0.5 \mathrm{msec}$, and $1.0 \mathrm{msec}$ after fuel injection. The value of $P_{\max }$ and $d P / d t$ was changed in accordance with the short ignition time after fuel injection. When ignition time is very advanced, ignition does not occur. This is because the flammable mixture around spark plug is not formed. Also, in case of retarded ignition time, the flammable mixture is diffused around spark plug owing to induced air flow. Thus, it is difficult to form the rich mixture around spark plug.

3.4.2 The relation of $(S v)^{*}$ and $d P / d t$ with stratification degree Figure 11 compares the results of $(S v)$ and $d P / d t$. The difference between $(S v)$ and $d P / d t$ is large from the middle to the end of the data. The value of $(S v)_{\max }$ is about $22 \%$ less than that of $(d P / d t)_{\max }$. The location of the maximum $P$ is not same that of $d P / d t$. As $P$ is larger, the mass burned fraction is increased at the same burning velocity because the unburned gas density is larger. As the interval after ignition start is longer, the value of $S v$ and $d P / d t$ is decreased. The reason for decreasing $S v$ and $d P / d t$ is that the stratified fuel is not formed near spark plug. We observed this phenomenon through the visualization result of flame propagation near spark plug. Therefore, $(S v)_{\max }$ is synthetically estimated in the terms outlined in section 2.3 (a) and (b) with stratification degree.

3.4.3 $(S v)_{\max }$ characteristics according to mixture distribution Figure 12 (a) and (b) show the results of $(S v)_{\max }$ measured using Eq. (11) according to mixture distribution in the case of the equivalence ratios 0.8 and 0.2. Where, the ordinate shows the ratio of $(S v)_{\max }$ and the highest value of $S v$ in case of $100 \%$ direct injection. Regardless of equivalence ratio, the value of $(S v)_{\max }$ is increased with increasing the rate of direct injection. That is, $(S v)_{\max }$ in $100 \%$ direct injection has the highest value because this case can stratify the mixture gas near the spark plug. We confirmed the stratification degree by comparing the combustion pressure with visualized flame propagation. From these results, we find that stratification degree suggested by this study can be used as the quantitative criteria for indicating stratified mixture condition when the fuel was concentrated near the spark plug and $(S v)_{\max }$ is useful as measure of the stratification degree. The results also lead to the conclusion, that is, the constant volume combustion chamber is useful for evaluating the early phase burning feature in an actual DI gasoline system.

\section{Conclusion}

( 1 ) We found that the turbulence intensity generated by the swirl flow in the chamber enhances the flame propagation speed and promotes the air fuel mixture. 


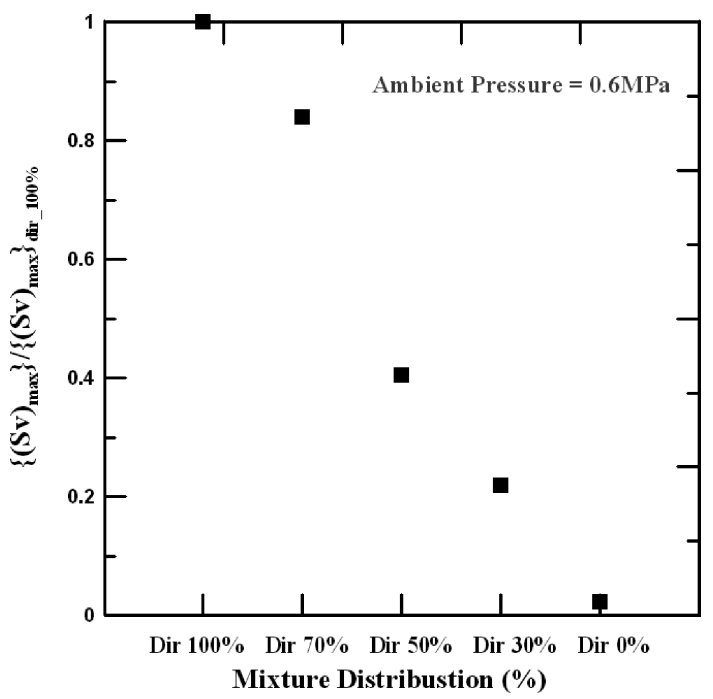

(a) $\Phi=0.8$

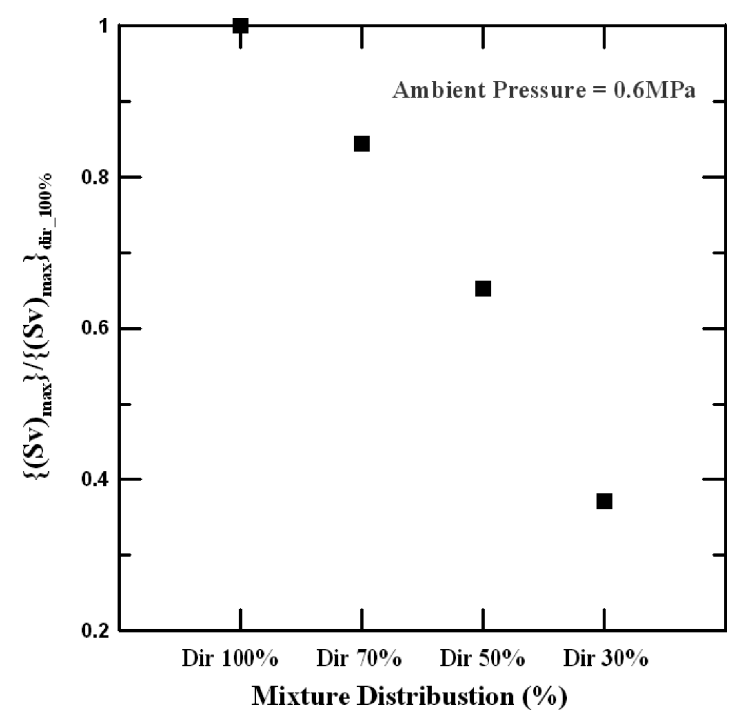

(b) $\Phi=0.2$

Fig. $12(S v)_{\max }$ as stratification degree at $P a=0.6 \mathrm{MPa}$

( 2 ) The following results obtained in this study correspond to the concept in actual DI system development.

1) As the swirl intensity increase, $(S v)_{\max }$ is rapidly enhanced and the period of combustion is shorten.

2) As the rate of direct injection increase, $(S v)_{\max }$ is increased.

3) $(S v)_{\max }$ deterioration by increasing the pre-mixture injection is mainly caused by the stratification effect, namely, the increased amount of unburned fuel.

( 3 ) As the swirl intensity increases in the combustion chamber, the combustion pressure is increased and the arrival time to peak combustion pressure is shortened. This revealed that the swirl flow enhance the flame area and promotes the air fuel mixture.

(4) The maximum volume burning velocity $(S v)_{\max }$ is introduced to the stratification degree and in the case of 100 percent direct injection, forming the rich mixture around the spark plug, the value of $(S v)_{\max }$ is highest. From this result, we found that $(S v)_{\max }$ is effective criteria to evaluate the stratified mixture condition.

\section{Acknowledgements}

We would like to thank Combustion Engine Research Center (CERC) for financial support for this work.

\section{References}

( 1 ) Moriyoshi, Y., Komatsu, E. and Morikawa, H., Analysis of Turbulent Combustion in Idealized Stratified Charge Conditions, COMODIA 2001, No.2-09, (2001), pp.226-231.

( 2 ) Jeong, D.S., Suh, S.W., Oh, S.M. and Chang, Y.J., An Experimental Study of the Effect of Flow on Flame Propagation in a Constant-Volume Combustion Chamber, KSAE, Vol.3, No.2 (1995), pp.136-145.

( 3 ) Kawahara, N., Tomita, E., Yoshiyama, S., Nishiyama, A. and Hamamoto, Y., Effect of Swirl Turbulent Flow Field and Inhomogeneous Concentration Field on Combustion of Fuel-Air Mixture in a Constant Volume Vessel, COMODIA 2001, No.2-08 (2001), pp.219225.

( 4 ) Lee, S.J., Lee, J.T. and Lee, S.Y., A Study on the Influence of Turbulence Characteristics on Burning Speed in Swirl Flow Field, KSME (B), Vol.20, No.1 (1996), pp.244-254.

( 5 ) Arcoumais, C. and Bae, C.-S., Visualization of Flow/Flame Interaction in a Constant-Volume Combustion Chamber, SAE Paper 930868, (1993).

( 6 ) Chekel, M.D. and Ting, D.S.-K., Turbulence Effects on Developing Turbulent Flame in a Constant Volume Combustion Chamber, SAE Technical Paper, 930867, (1984), pp.301-305.

( 7 ) Lewis, B. and Elbe, V., Combustion, Flames and Explosions of Gases, (1987), Academic Press. 